\title{
17. Inhibitory Effect of Early Postnatal Injections of Cortisone Acetate on Vaginal Mitotic Activity in Neonatally Estrogenized, Ovariectomized Adult Mice*)
}

\author{
By Noboru TAKasUgI**) \\ Zoological Institute, Faculty of Science, University of Tokyo
}

(Comm. by Yô K. OKADA, M. J. A., Jan. 12, 1970)

It is well established that the vaginal epithelium is proliferated and cornified in neonatally estrogenized adult mice and moreover, the states of vaginal epithelium were not affected by ovariectomy or by transplantation of the vaginae into ovariectomized 'normal' hosts. It has also been demonstrated that the vagina of such animals is different from that of the normal females in alkaline phosphatase activity and in responses to antiestrogenic steroids (Takasugi, 1963; Kimura, 1967; Mori, 1967; Kohrman and Greenberg, 1968; for review, see Takasugi, Kimura and Mori, 1969).

On the other hand, the inhibitory effects of cortisone or cortisol on the development of hyperplastic or cancerous lesions in various organs in mice are well documented (for review, see Stock, 1952; Noble, 1957). Accordingly, it was thought interesting to study the mitotic activity of vaginal epithelial cells in ovariectomized adult mice given injections of estrogen plus cortisone acetate during a neonatal period.

Materials and methods. Thirty-eight mice of the C57 Black/Tw strain from the colony maintained in this laboratory were used for these experiments. Four mice ovariectomized at 60 days of age were sacrificed 42 days later as controls (Group A). Four mice (Group B) were injected with $20 \mu \mathrm{g}$ cortisone acetate, and 6 mice (Group C) with $20 \mu \mathrm{g}$ estradiol-17 $\beta$, both dissolved in $0.02 \mathrm{ml}$ sesame oil for 10 days starting on the day of birth.

Mice of Groups D-I were given 10 daily injections of $20 \mu \mathrm{g}$ estradiol and $20 \mu \mathrm{g}$ cortisone acetate. Estradiol administration was always commenced on the day of birth but the day of the first injection of cortisone acetate varied among different groups, from the first to the 6th postnatal day (Fig. 1). The volume of oil vehicle was 0.02

*) This investigation was supported by a Grant-in-Aid for Fundamental Scientific Research from the Ministry of Education of Japan.

**) Present address: Department of Biology, Faculty of Science, Okayama University, Tsushima, Okayama. 


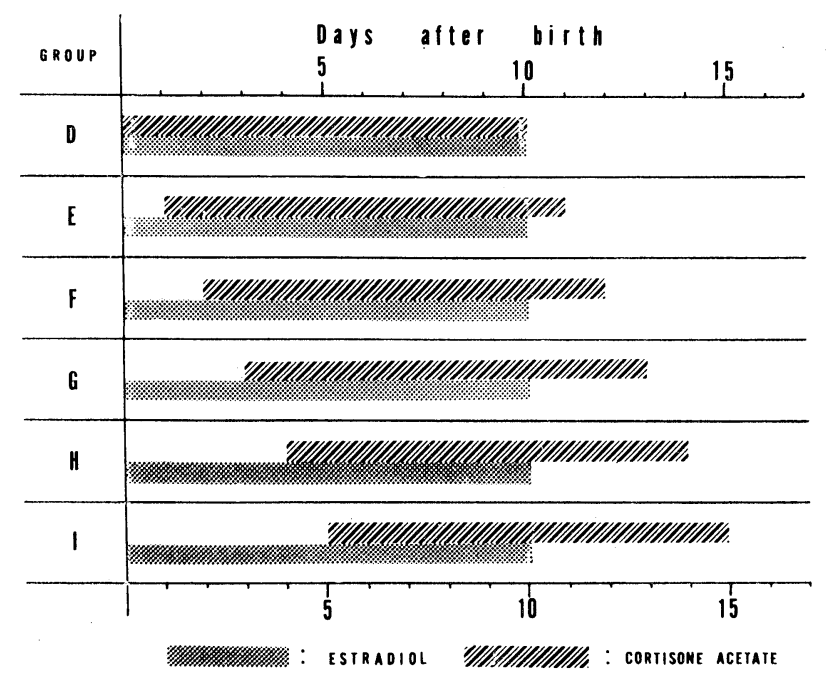

Fig. 1. Combinations of injection periods of estradiol and cortisone acetate.

$\mathrm{ml} /$ day.

All mice were ovariectomized between 58 and 62 days of age and sacrificed at 100-115 days, 5 hours after a single subcutaneous injection of colchicine, $100 \mu \mathrm{g}$ per $20 \mathrm{~g}$ body weight, dissolved in $0.1 \mathrm{ml}$ of a $0.9 \% \mathrm{NaCl}$ solution. Vaginae were fixed in Bouin's fluid, sectioned in paraffin at $8 \mu$ and stained with Delafield's hematoxylin and eosin or hematoxylin-phloxine-alcian blue-orange $G$ following the differential staining method for keratin and mucin (Dane and Herman, 1962).

Mitotic figures per 500 and 2,000 cells were counted in the basal and intermediate layers of the vaginal epithelium, respectively, in both the cranial and caudal parts of vagina. According to Forsberg (1963), the two parts are of the different origin, the cranial $3 / 5$ from the Müllerian duct and the caudal 2/5 from the urogenital sinus. The percentage of dividing epithelial cells arrested at metaphase is referred to as the mitotic rate in this paper.

Results. In both ovariectomized 'normal' and ovariectomized neonatally cortisone-treated mice (Groups A and B), the vaginal epithelium consisted of 2-3 layers of cells, the mitotic rates being low throughout the vagina. The mitotic rate of vaginal epithelial cells was higher in the basal layer of the cranial part of vagina in neonatally estrogenized, ovariectomized mice (Group C). The mitotic rate in the caudal vagina was lower than in the cranial (Table I). Injections of cortisone acetate in combination with estradiol definitely lowered the mitotic rate in the basal layer of the cranial vagina (Groups D-G). In particular, in mice of Groups F and G which had 
Table I. The mitotic rate $(\%)$ in the basal and intermediate layers of the epithelium of the cranial and caudal parts of vagina in neonatally estrogenized, ovariectomized adult mice

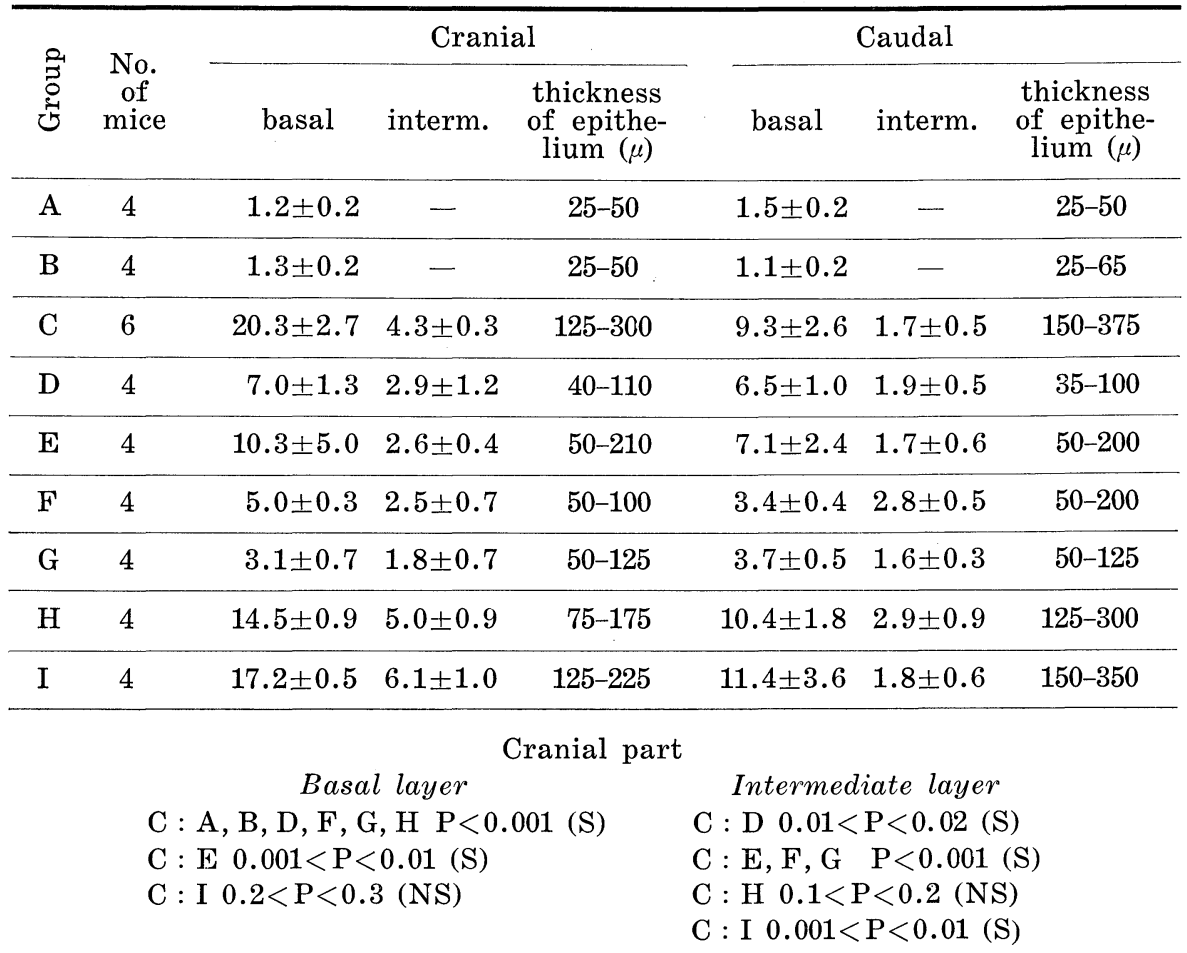

Caudal part

\begin{tabular}{|c|c|}
\hline Basal layer & Intermediate layer \\
\hline $\mathrm{C}: \mathrm{A}, \mathrm{B} \quad \mathrm{P}<0.001(\mathrm{~S})$ & $\mathrm{C}: \mathrm{D} \quad 0.3<\mathrm{P}<0.4(\mathrm{NS})$ \\
\hline $\mathrm{C}: \mathrm{D} \quad 0.05<\mathrm{P}<0.1(\mathrm{NS})$ & $\mathrm{C}: \mathrm{E} \quad 0.8<\mathrm{P}<0.9(\mathrm{NS})$ \\
\hline $\mathrm{C}: \mathrm{E} 0.2<\mathrm{P}<0.3(\mathrm{NS})$ & $\mathrm{C}: \mathrm{F}, \mathrm{H} \quad 0.001<\mathrm{P}<0.01(\mathrm{~S})$ \\
\hline $\mathrm{C}: \mathrm{F}, \mathrm{G} 0.001<\mathrm{P}<0.01(\mathrm{~S})$ & $\mathrm{C}: \mathrm{G} 0.5<\mathrm{P}<0.6(\mathrm{NS})$ \\
\hline $\mathrm{C}: \mathrm{H} \quad 0.4<\mathrm{P}<0.5(\mathrm{NS})$ & $\mathrm{C}:$ I $0.6<\mathrm{P}<0.7(\mathrm{NS})$ \\
\hline $\mathrm{C}:$ I $0.3<\mathrm{P}<0.4$ (NS) & \\
\hline
\end{tabular}

received injections of cortisone acetate for 10 days commencing on the second and third day of postnatal life, respectively, the mitoses of epithelial cells of the basal layer of the cranial vagina were greatly reduced in number as compared with Group C animals. The mitotic rate in the basal layer of the caudal vagina was lower in these two groups than in the other. Injections of cortisone acetate from the 5 th postnatal day onward were less effective in inhibiting mitoses in cells of the basal layer of the epithelium of both the cranial and caudal parts of vagina. The mitotic rate in the intermediate layer of the cranial vagina was lower in Groups D-G than in Group C. It was a little higher in Group I than in Group C. Group F and H mice showed 
higher mitotic rate in the intermediate layer of the caudal vagina than animals of the other groups.

In neonatally estrogenized, ovariectomized mice (Group C), the vaginal epithelium was highly proliferated and cornified, its basal cells occasionally possessing downgrowths extending into the connective tissue stroma. As shown in Table I, the vaginal epithelium was thinner in both the cranial and caudal parts of vagina in Groups D-G than in Group C. In Groups A and B, the vaginal epithelium consisted of 2-3 layers of cells while in Groups D-G it was composed of 4-6 layers of cells, with some areas where the basal and intermediate layers were distinguishable and squamous transformation or slight cornification was occurring. In mice of Group I, the vaginal epithelium was more strongly proliferated than in those of Groups D-H. The superficial cornified layers were well developed in Group I animals like those in neonatally estrogenized mice (Group C). Animals of Groups C-I showed a small number of mucous cells stained with alcian blue in the epithelium lining the cervical end of the cranial vagina.

Discussion. Proliferation and cornification of the vaginal epithelium were not abolished by ovariectomy in adult mice which had received 10 daily injections of estradiol from the day of birth. If injections of cortisone acetate were given for 10 days beginning on the 1st-4th postnatal day in neonatally estrogenized mice, mitoses in the epithelium of the cranial part of vagina were reduced in number. Mitoses in the epithelium of the caudal vagina was also inhibited in those mice given cortisone injections from the 3rd or 4th postnatal day onward. The inhibitory effect of cortisone acetate was less marked in both the cranial and caudal parts of vagina in animals having received injections after the 4 th postnatal day. It is of interest that cortisone treatment begun on the $3 \mathrm{rd}$ or the 4 th postnatal day inhibited the mitotic activity and proliferation of the epithelium of the caudal vagina more than a similar treatment commenced on the day of birth. The cortisone treatment from the 6 th postnatal day on no longer suppressed the mitotic activity in the basal layer of the epithelium of both the cranial and caudal vaginal parts in neonatally estrogenized mice.

Mori $(1968,1969)$ reported that neonatal injections of vitamin A completely inhibited the occurrence of estrogen-independent proliferation and cornification of the vaginal epithelium in neonatally estrogenized mice. In the present experiments, combined injections of estradiol and cortisone acetate during early postnatal life were never followed by total disappearance of the permanent vaginal changes. It seems evident that cortisone was less effective in this 
respect than vitamin $\mathrm{A}$, at least at dosages used in these experiments. Summary. The epithelium lining the vaginae of adult C57 Black/Tw mice which had received injections of $20 \mu \mathrm{g}$ estradiol for 10 days from the day of birth exhibited continued proliferation and cornification. The states of the vagina were estrogen-independent, not being affected by ovariectomy. The effects of neonatal estradiol injections on the vagina were greatly impaired by injections of $20 \mu \mathrm{g}$ cortisone acetate given for 10 days commencing on the third or fourth postnatal day, as evidenced by marked reduction in the mitotic activity and proliferation of vaginal epithelial cells in ovariectomized adult mice which had been treated with the two steroids.

Acknowledgement. The author wishes to thank Emeritus Professor K. Takewaki of Tokyo University for his valuable discussion during the course of the present study and for his kind help in preparing the manuscript.

\section{References}

Dane, E. T., and D. L. Herman (1962): Stain Technol., 38, 97.

Forsberg, J.-G. (1963): Derivation and differentiation of the vaginal epithelium. Dissertation, Univ. Lund, p. 197.

Kimura, T. (1967): J. Exp. Zool., 165, 71.

Kohrman, A. F., and R. E. Greenberg (1968): Devel. Biol., 18, 632.

Mori, T. (1967): Annot. Zool. Japon., 40, 82.

- (1968): Ibid., 41, 113.

- (1969): Proc. Japan Acad., 45, 115.

Noble, R. L. (1957): Pharmacol. Rev., 9, 367.

Stock, C. C. (1952): Ciba Found. Colloq. on Endocrinology, 1, 135.

Takasugi, N. (1963): Endocrinology, 72, 607.

Takasugi, N., Kimura, T., and T. Mori (1969): Proc. Symp. on Postnatal Development of Phenotype, Praha (in press). 